\title{
PROPOSAL OF A METHODOLOGY FOR THE PERFORMANCE OF FUNCTIONAL AND CLINICAL TESTING OF MEDICAL DEVICES DESIGNED AND MANUFACTURED BY COVID 19, THROUGH THE USE OF INFORMED CONSENT
}

\author{
WILVER AUCCAHUASI ${ }^{1}$, CHRISTIAN OVALLE ${ }^{1}$, EDWARD FLORES ${ }^{1}$, FERNANDO SERNAQUÉ $^{2}$, \\ EDDY MAGUIÑA ${ }^{2}$, MARIA RODRIGO ${ }^{2}$, FAVIOLA FARFÁN ${ }^{3}$, AMAURY FARFÁN ${ }^{3}$, EDWIN FELIX $^{3}$, \\ GLORIA ROJAS ${ }^{4}$ \\ ${ }^{1}$ Universidad Privada del Norte, Lima, Perú \\ ${ }^{2}$ Universidad Nacional Federico Villarreal, Lima, Perú \\ ${ }^{3}$ Instituto Peruano de Investigación en Ingeniería Avanzada, Lima, Perú \\ ${ }^{4}$ Servicio Nacional de Aprendizaje SENA- Region Caldas, Manizales, Colombia
}

\begin{abstract}
The effects of the pandemic caused by COVID-19, are causing the development of medical implements and equipment quickly, in some cases due to the emergency situation authorizations are being granted for the manufacture, marketing and use. In many cases these developments are motivated by a local need that can help mitigate the effects of COVID-19. It is in this scenario, where we present a methodology to be able to collaborate in that these developments, providing recommendations of good practices for the functional testing stage, based on the design of the test protocols and informed consent, with these testing mechanisms, are It can be presented to a health ethics committee, with the intention that it be approved for subsequent application. With the completion of the studies using the equipment developed and having passed the study protocol, the results of the study guarantee that the equipment developed can be approved for registration, commercialization and subsequent clinical use. The use of the study protocol with the informed consent helps in the clinical tests of the device, the regulatory requirements must be taken into consideration for the development of the equipment that ensures the safety and integrity of the patients when they use the medical devices.. The results presented are based on the considerations to be taken into account at the time of writing the study protocols and the respective informed consents.
\end{abstract}

KEYWORDS: Temperature Controller Design, Hardware and Software, Temperature Control System

Received: Jun 08, 2020; Accepted: Jun 28, 2020; Published: Sep 15, 2020; Paper Id.: IJMPERDJUN20201237

\section{INTRODUCTION}

In the development of medical devices, functional tests are of vital importance to verify the technical specifications presented in the design stage and implemented in the development stage. The mechanism for performing functional tests is characterized by tests on real patients, therefore it is required to inform future patients who will check the functionalities of the equipment developed. It is in this process where it is required to inform the future patient of all information related to the equipment and the procedures to be carried out in the study. Performing a review of the literature, we found the following works where a methodology is presented to be able to use informed consent in the design of medical equipment, as a mechanism of knowledge in functional tests [1]. The needs for development are evident in countries that have not managed to advance in the development of medical equipment and be able to commercialize them, for which it is necessary to start designing equipment with this 
objective [2]. Studies based on testing multiple medical equipment and tests are commonly performed based on a methodology to be able to analyze their use and behavior of the subjects that are the object of the research [3]. In the medical field, new challenges are being presented, which allows new care protocols to be implemented, which is why many studies are required for their approval; the use of informed consent helps to achieve these objectives [4].

\section{METHODS \& MATERIALS}

In the functional tests to be carried out by the development team, information about the equipment to be tested must be considered, as well as the test protocol where it indicates the procedures to be carried out, as well as the choice of possible patients that will be part of the study and in whom the developed equipment will be tested. Below is a block diagram where it indicates the procedures to follow from the choice of the equipment to be developed to the functional tests of the equipment:

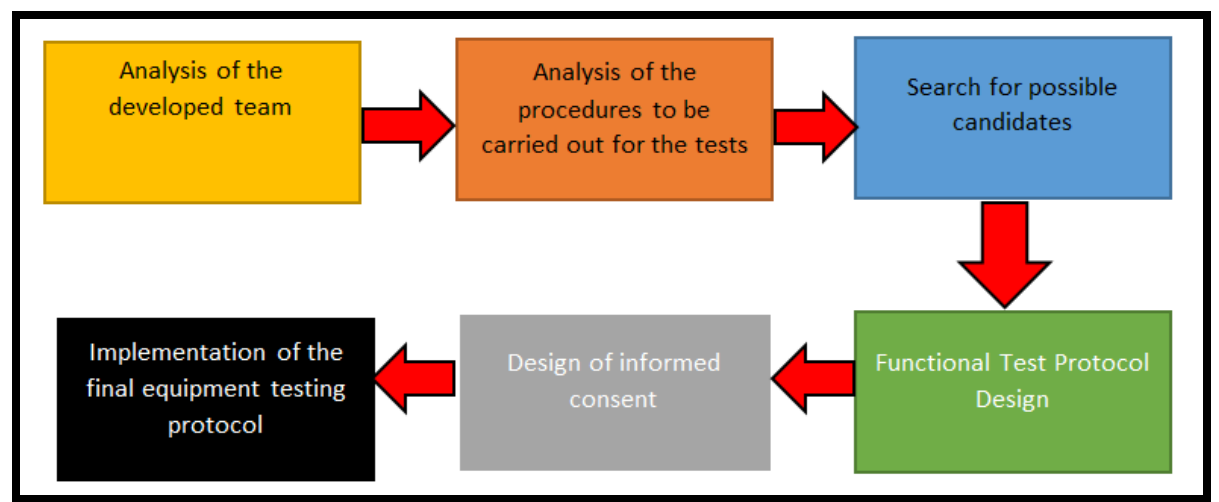

Figure 1: Block Diagram of the Proposal.

\section{Analysis of the Developed Team}

In the analysis of the equipment to be developed, the technical specifications must be taken into account, in addition to this, it is recommended to carry out a detailed study of similar equipment that is on the market and is marketed, this study is important because it will allow to compare the functionalities and mainly locate it in which classification is the equipment to be able to define the regulations that must be met in the design of the equipment.

\section{Analysis of the procedures to be Carried out for the Tests}

When you have the technical characteristics of the equipment and having been located in its corresponding classification, the next step is to evaluate the safety tests that must be considered in the design of the equipment so that it can pass the evaluations and be able to register for its commercialization. The location of the classification according to the American FDA standard, would allow to know which safety tests must be fulfilled.

\section{Search for Possible Candidates}

After the development of the equipment, it is necessary to carry out functional tests, for this purpose it should be considered to test in real patients, to check the functionalities of the equipment and verify the degree of compliance with the functionalities described in the design objectives. The choice of the possible candidates for the equipment tests is of vital importance because the success of the equipment functionality studies will depend on them, it is recommended to locate the best candidates that meet and have a direct relationship with the equipment specifications, to have the safety of 
the compliance of the equipment it is important to have carried out an analysis of the specifications of the commercial equipment that is similar and to have considered in its design, the same safety considerations that are applicable to current regulations; With this analysis, it is certain that the tests do not present problems of a major nature and with patients who meet the conditions of the equipment, there would be no problems in conducting the study.

\section{Functional Test Protocol Desing}

The study for the tests of the developed equipment, would allow to demonstrate the fulfillment of the objectives proposed at the beginning of the project design. One of the main components of the study is the design of the study protocol, for which it is necessary to plan all the procedures, tasks, times, possible results to be obtained, this information must be detailed in a practical way and in a logical sequence, to That the ethics committee can analyze the protocol with greater criteria and that the patients who will be the object of study, at the time of reading the protocol, understand that it consists of the study to which they will be subjected.

\section{Desing of Informed Consent}

Informed consent is of vital importance in conducting the study, through informed consent the signed consent is obtained from the patients who will be the subject of the study, it is recommended to include the greatest amount of information in the informed consent, with the purpose that The candidates for the study can choose their participation with the best knowledge of the equipment, the procedures to be carried out and the security that is considered in the development of the equipment.

\section{Implementation of the Final Equipment Testing Protocol}

The final protocol for conducting the study that demonstrates compliance with the technical specifications of the equipment and the level of patient safety, accompanied by informed consent, it is recommended to consider in the final protocol the greatest amount of information, such as procedures to be performed, the patient safety considerations, data management and information product of the study.

Normally, the protocol is made up of the procedure to be carried out and the informed consent, in this study it is considered to include the safety considerations that were considered in the development of the equipment, so that the candidates can know in a greater level of detail the safety considerations that have been implemented in the medical device under study.

\section{RESULTS}

The results that are reached in the present investigation are related to presenting the considerations to be included in the information presented in the test protocol, with emphasis on considerations related to patient safety, in such a way that the future patient that will be the object of the study, you can know all the considerations implemented in the equipment so that you can choose your participation with the greatest amount of information, not only about the use and applications of the equipment, but also all the regulatory requirements that were met in order to get to the final design that will be tested. The required information is presented as a model of the test protocol and its respective informed consent. 


\begin{tabular}{|l|l|l|}
\hline Name of the standard & Issued by & $\begin{array}{l}\text { The standard ensures in the } \\
\text { patient }\end{array}$ \\
\hline $\begin{array}{l}\text { IEC 60601-1-1-1(1988-12) } \\
\begin{array}{l}\text { Medical electrical equipment } \\
\text { fort 1: general requirements }\end{array}\end{array}$ & IEC1 (laboratory name) & $\begin{array}{l}\text { Ensures the protection of the } \\
\text { patient in situations of } \\
\text { electric shock, in the use of } \\
\text { the equipment }\end{array}$ \\
\hline
\end{tabular}

Figure 2: List of Standards, Laboratory and Application of the Standard for the Benefit of the Patient.

In Figure 2, a list of standards that have been met in the design and manufacture of the medical device is presented, as well as the entity where the test was performed and its corresponding involvement with patient safety. This information is very important because the patient who will be the object of the study has knowledge of the technical considerations that have been taken in the design of the equipment and that comply with international standards (American FDA), causing them to make a better decision to participate. in the study. It is recommended that this information be considered in the study protocol.

Just as we present the technical considerations based on international standards that have been taken into consideration, below we present a guide for the design of informed consent, considering the greatest amount of information for the benefit of the patient and the study to be carried out.

\section{Guide for the Preparation of the Informed Consent Document, for Functional Tests of Medical Devices}

Informed consent will be documented through the use of a written format approved by an ethics committee and signed by the participant or her representative, and if necessary, that of a witness.

We suggest that such consent is not drawn up continuously, but separated into sections and should consider the following information:

- Title of the project

- Team of Researchers / name of position in the project, institution, telephones)

- Description of the medical device to be tested (Technical data regarding the electrical safety of the patient)

- Introduction / Purposes

- Participation

- Procedures

- Risks / discomforts related to the procedure

- Risks regarding the medical device to be tested

- Benefits

- Alternatives

- Compensation

- Confidentiality of information

- Problems or questions

- Consent / voluntary participation

- Names and signatures of the participant or legal guardian 


\section{CONCLUSIONS}

The conclusions reached are related to being able to provide future patients with the greatest amount of information so that they can choose whether to participate in the study related to the functional tests of the equipment. Normally, future patients are presented with the study protocol, which includes information related to the steps to be taken in the tests, as well as the purpose of the study and their informed consent, leaving a gap in technical information related to safety. of the patient, even more so when medical equipment is being evaluated where there is a strong commitment to patient safety, either in equipment that guarantees the continuity of the patient's life, that is why it is proposed to consider information related to the design of the equipment and what protection measures have been taken to mitigate and / or eliminate these risks to the patient, it is important that the future patient has full knowledge of the equipment developed and compliance with current regulations, in this way they can have more information and can choose with better criteria, their participation in the study to check the functioning of the medical equipment.

It should be taken into account that in this pandemic caused by COVID-19, many researchers will develop prototypes of medical devices such as artificial respirators, so it is recommended to consider current regulations in their design to ensure the integrity of the patient and is in In this context, information related to patient safety is required to be considered in the information presented to the patient through the test protocol and informed consent, in this way the future patient can choose to participate in the study.

\section{REFERENCES}

1. Grisi Bernardo Santiago, Wilver Auccahuasi Aiquipa, Madelaine Bernardo Santiago, Alfonso Fuentes, Carlos Venturo Orbegozo, Denis Morales Saavedra, Sergio Arroyo Rivera, and Edward Flores Masias. 2019. Electromagnetic compatibility tests and informed consent, in the development of research on biomedical equipment design. In Proceedings of the 5th International Conference on Communication and Information Processing (ICCIP '19). Association for Computing.

2. Colmachi, E., \& Luis, J. (2016). Importación de equipos médicos de diagnóstico no invasivo desde China (Bachelor's thesis, Quito: Universidad de las Américas, 2016.).

3. Moreno, E. M., \& García Torres, F. (2017). Metodología para la elaboración de guías de intervención basadas en la evidencia en psicología y salud mental: procedimientos del NICE.

4. Barrera-Cruz, A., Viniegra-Osorio, A., Valenzuela-Flores, A. A., del Pilar Torres-Arreola, L., \& Torres, J. D. (2016). Metodología para el desarrollo y la actualización de guías de práctica clínica: estado actual. Revista Médica del Instituto Mexicano del Seguro Social, 54(1), 78-91. 
